\title{
Improving the politics of biotechnological innovations in food security and other sustainable development goals
}

\author{
Alan Raybould $\mathbb{D}$
}

Received: 1 July 2021 / Accepted: 29 July 2021 / Published online: 5 August 2021

(C) The Author(s), under exclusive licence to Springer Nature Switzerland AG 2021

\begin{abstract}
The unwarranted interference of some environmental non-governmental organisations (ENGOs) in decision-making over genetically modified (GM) crops has prompted calls for politics to be removed from the regulatory governance of these products. However, regulatory systems are inevitably political because their purpose is to decide whether the use of particular products will help or hinder the delivery of public policy objectives. ENGOs are most able to interfere in regulatory decision-making when policy objectives and decision-making criteria are vague, making the process vulnerable to disruption by organisations that have a distinct agenda. Making regulatory decision-making about GM crops and other green biotechnology more resistant to interference therefore requires better politics not the removal of politics. Better politics begins with political leadership making a case for green biotechnology in achieving
\end{abstract}

This comment refers to the article available online at https:// doi.org/10.1007/s11248-021-00261-y.

A. Raybould ( $\square)$

Innogen Institute, School of Social and Political Science, The University of Edinburgh, Old Surgeons' Hall,

Edinburgh EH1 1LZ, UK

e-mail: alan.raybould@ed.ac.uk

A. Raybould

Global Academy of Agriculture and Food Security, Easter

Bush Campus, The University of Edinburgh,

Midlothian EH25 9RG, UK food security and other sustainable development goals. Such a policy must involve making political choices and cannot be outsourced to science. Other aspects of better politics include regulatory reform to set policy aims and decision-making criteria that encourage innovation as well as control risk, and engagement with civil society that discusses the values behind attitudes to the application of green biotechnology. In short, green biotechnology for sustainable development needs better politics to counter wellorganised opposition, to encourage innovation, and to build the trust of civil society for these policies. Removing politics from regulatory governance would be a gift to ENGOs that are opposed to the use of biotechnology.

Keywords Policy choices - Regulatory policy · Decision-making criteria $\cdot$ Public engagement $\cdot$ Civil society $\cdot$ Trust

\section{Introduction}

Biotechnology has enormous potential to contribute to sustainable development. Medical (red) and industrial (white) biotechnology are relatively uncontentious, whereas biotechnology in agriculture, environmental management and public health (green biotechnology) (Kafarski 2012) continues to be controversial more 
than 25 years after the first commercial cultivation of genetically modified (GM) crops. A recent review by Smyth et al. (2021), "Removing politics from innovations that improve food security", contends that political opportunism by some environmental nongovernmental organisations (ENGOs) fosters this controversy through campaigns of disinformation and misinformation intended to disrupt regulatory decision-making and create a significant barrier to wider adoption of GM crops. As the use of GM crops increases crop yield, and provides other benefits including improved water use efficiency and reduced human and animal exposure to highly hazardous mycotoxins, Smyth et al. ask whether ENGO's opposition to GM crops is unethical.

Smyth et al. provide convincing evidence that cultivation of GM crops increases yield and I think that they are right to raise questions about the ethics of organisations that for opportunistic and self-interested reasons oppose use of this technology. However, I wish to offer a different view on the role of politics. While providing accurate scientific information helps to refute many claims made by ENGOs about GM crops, realising the potential of biotechnology to deliver food security and other aspects of sustainable development will require political leadership. Failing to make a political case for the use of biotechnology will leave the field open for ENGOs to make the opposing case and may exacerbate the problems that Smyth et al. highlight. We need to improve rather than remove politics to promote innovative use of biotechnology.

"Politics" is often used pejoratively (playing politics, party politics) and portrayed as something nefarious that is opposed to or regrettably complicates decision-making involving science. Davison (2010) refers to the "political meddling" of the EU's Council of Agricultural Ministers in regulatory decisions about GM crops following a scientific risk assessment. It is probably this sense of politics that Smyth et al. mean in the title of their commentary.

However, politics also has a more positive connotation: it is the forum in which individuals and organisations within society promote their legitimate values, ethics and interests; it is the means by which society evaluates these opinions to set societal objectives; and it the means by which society assesses options for achieving these objectives. It is in this sense that I want to argue that society needs better politics in discussions of biotechnology and sustainable development. Improving politics for biotechnology requires leadership by people with legitimate authority to make decisions on behalf of society (political leaders): they should make clear choices about how sustainable development should be defined and the role of biotechnology in its pursuit; they should adapt regulations to foster the innovation necessary for biotechnology to contribute most effectively to sustainable development; and they should encourage responsible engagement with these ideas by civil society to build trust.

\section{Making choices}

During the SARS-CoV-2 pandemic, governments tried to remove politics from decisions about protecting public health by claiming to "follow the science". However, protecting public health requires political debate to ascribe values to particular outcomes because resources are limited and trade-offs must be made; for example, deciding to prioritise treatment of COVID-19 meant fewer resources for diagnosing cancer (Dinmohamed et al. 2020), although treating viral diseases and diagnosing cancer are both aspects of protecting public health.

"Following the science" flourishes when a stated aim, such as justice or fairness, is virtually impossible to disagree with and everyone has a different, unstated idea of what the aim means. Whyte (2003) calls such aims "hooray words". "Protecting public health" is hooray word as no one is likely to advocate for endangering public health. The difficulty is agreeing what outcome would be the best for public health given current conditions and the resources available. In claiming to follow the science about SARS-CoV-2, political leaders abrogated their responsibility to justify their choices in prioritising particular aspects of public health. Failure to justify choices led to loss of trust in politicians and public officials and increased controversy and social divisions (de Campos-Rudinsky and Undurraga 2021). Better politics would have acknowledged that political choices are essential and unavoidable, justified the choices that were made, and explained how science was used to try to achieve them. Removing politics is simply pretending that science can eliminate the need to make choices. 
EU decision-making about the cultivation of GM crops is another example of following the science. Here the hooray words are safety and scientific certainty. Who would advocate for danger and uncertainty? However, since nothing is free from risk and science is never certain, choices must be made about what risks and levels of scientific uncertainty are acceptable. If these choices are not made, decisionmaking criteria cannot be set, which leads to serious problems: decisions can be postponed indefinitely while research is done in the endless quest for scientific certainty and zero risk, and ENGOs can complain that there is no consensus on GM crop safety (Hilbeck et al. 2015). Some EU decisions about cultivation of GM crops are still pending after more than 20 years of deliberation owing to continual requests for additional data. These requests are almost certainly a cover for political leaders who are unwilling to make potentially controversial choices (Mastroeni et al. 2021). Trying to end this stalemate by objecting to political meddling or advocating for science-based decisions (i.e., removing politics) can only make matters worse. Better politics is required to force political leaders to make explicit the policy choices that are necessary for the regulatory system to work.

Smyth et al. (2021) state that 4485 risk assessments have been performed on GM crops without any evidence arising that the risks they pose for human and animal health or the environment are different from non-GM counterparts. Hence, safety and scientific uncertainty ought to lose their power as reasons to delay decisions or as the basis of ENGO campaigns against GM crops. However, food security and sustainable development are hooray words that can step in and perform the same role as safety. No one is likely to advocate for food insecurity or unsustainable development. However, defining these terms, choosing priorities and evaluating options for delivery requires political leadership (Persson et al. 2016).

A persistent argument against green biotechnology is that it is unsustainable; it reduces food security in the long term because it promotes industrial agriculture (Crouch 1995) or because its effects are too unpredictable (Wilson 2021). As "in the long term" can be extended indefinitely, these are statements that green biotechnology cannot contribute to food security by definition. This position cannot be refuted solely by appeals to data on GM crop yield because the point of disagreement is not whether GM crops increase yield, it is whether current increases in yield produced by GM crops should be regarded as greater food security.

Repudiating the view that today's higher yields from GM crops do not constitute an increase in food security requires a principled choice to define food security and green biotechnology as being compatible, followed by political leadership to advocate for that position and make it public policy. Improving rather than removing politics is needed to stop ENGOs, standards-setting bodies and trade organisations with vested interests from convincing society to exclude green biotechnology from its definitions of food security and sustainability generally. Without such political leadership, innovation in green biotechnology for sustainable development will be severely curtailed as developers will lose confidence that there will be a market for their products.

\section{Regulatory policy}

Innovation for sustainable development should be driven by societal needs ("society pull") rather than by technological developments ("technology push") (Vollenbroek 2002). Regulatory policy for GM crops has tended to focus on controlling risk from technology push rather than enabling society pull to encourage innovation. Indeed, some regulatory systems exclude consideration of the potential benefits of GM products (Bartsch 2014). This policy has constrained innovation as shown by the narrow range of products - most GM varieties are herbicide-tolerant and insect-resistant commodity crops - and product development being limited largely to a handful of multinational companies (Bonny 2017).

The advent of gene-edited (GE) crops has stimulated a discussion about this constraining effect of GM regulations, especially as defining GE crops as nonGMOs appears to increase innovation as measured by the number of product developers and product types (Whelan et al. 2020). Unfortunately, a focus on the legal definition of GMOs seems to be side-lining debates about the purpose and effectiveness of GM regulation.

A typical approach is that of the UK Government's Taskforce on Innovation, Growth and Regulatory Reform (TIGRR 2021). TIGRR recommended that 
GE products should not be considered as GM: "we should adopt the Cartagena protocol definition which allows the interpretation that simple GE is not considered to be GM". TIGRR did not recommend wholesale reform of GM regulations, however, because that would be "divisive, complex and contested", and because it believes that GE can deliver most of the benefits that GM could. This view seems misguided about the potential of GM, ignores the possibility of future new biotechnology that may be captured by GM regulations and is a missed opportunity to examine whether GM regulations meet societal needs for innovation.

How should GM regulations be reformed to promote innovation? A good start would be to reduce or eliminate data requirements, such as phenotypic characterisation, compositional analysis and molecular characterisation studies, that assess unintended effects of the technology rather than risks posed by the product. These studies are expensive and time-consuming but provide data of unspecified relevance to decision-making (Layton et al. 2015; Raybould and Macdonald 2018). In essence, they seek to discover all the differences between a GM crop and a non-GM comparator and then work out whether any of the differences are "biologically relevant".

Judging biological relevance has elements of science, such as arguments along the lines "if the crop has trait $\mathrm{X}$ then it is likely to lead to outcome $\mathrm{Y}$ when cultivated". However, relevance must ultimately be defined by societal choices made through politics: is outcome Y beneficial, harmful or neither? (Raybould et al. 2019) A better approach to regulatory risk assessment would be to define clearly those outcomes that are unacceptable and deduce a set of crop traits that plausibly indicate those outcomes could occur if the product were used. Data requirements would then be limited to tests of the hypothesis that the crop possesses none of those traits (Raybould 2019). Eliminating uninformative phenotypic, compositional and molecular profiling data requirements ought to reduce regulatory costs considerably for both developers and regulators and allow more resources to be allocated to innovation.

Of even greater value would be inclusion of potential benefits in regulatory decision-making. The approach should mirror that described above for risk assessment. A benefit assessment would work back from the aims of society, such as reducing greenhouse-gas emissions, to definitions of attributes of products and methods of use that are likely to deliver those benefits. The assessment would focus on the extent to which a product and the proposed method of use have those attributes. Decisionmaking would require a method of weighing the likelihood and value of the potential benefits (the opportunity) against the risk (Sanvido et al. 2012). Decision-making could also include whether the product meets certain voluntary standards, such as the British Standards Institution Responsible Innovation Guide that provides a framework for product developers to show how they have sought to minimise the risks and maximise the potential societal benefits of their product (Tait et al. 2021).

The above can only sketch how regulations could promote innovation. The key point is that many political choices must be made to design effective regulations that have clear policy aims and decisionmaking criteria: what balance of controlling immediate risk and promoting innovation (controlling longterm risk) are the regulations intended to deliver; how should societal benefit and harm be defined; how should acceptable risk be defined (e.g., always on the basis of net opportunity or are some risks unacceptable regardless of the amount of opportunity); how are we to judge whether a hypothesis about risk or opportunity has been tested sufficiently; and so on.

Although regulatory decisions will rely on scientific data, the purpose of regulations is to achieve policy aims. Consequently, the scientific aspects of regulatory decision-making must follow from political choices about the aims of policy and how judgements will be made. Reform of regulations to promote innovative green biotechnology to achieve sustainable development therefore will come from better politics not by removing politics altogether.

\section{Civil society}

Anecdotal evidence suggests that regulators tend to tighten regulations and increase data requirements to try to reduce public concerns about green biotechnology (Herman et al. 2021). Any change in regulatory philosophy towards promotion of innovation in green biotechnology is likely to face opposition from organisations such as some ENGOs, sections of the media and standards-setting bodies in sectors such as organic agriculture. To avoid these groups dominating 
debates and blocking regulatory change by heightening public anxiety, political leaders must communicate effectively to civil society about the advantages of green biotechnology for sustainable development.

Opponents of GM crops may be classified as interestbased or ideology-based; sometimes referred to as NIMBYs (not in my back yard) and NIABYs (not in anyone's back yard), respectively. They react very differently to the provision of information and reasonable debate. NIMBYs regard information and discussion as useful ways to resolve conflicts, whereas NIABYs see information as propaganda and discussion as betrayal (Tait 2001). Consequently, if opposition to GM crops by certain ENGOs is ideological, provision of information and discussion will not change their minds nor increase their trust. In these circumstances, it is better to accept that constructive debate is impossible and prevent such organisations from disrupting policy- and decisionmaking. Participation in policy discussions could be limited to groups that undertake to engage constructively, thus extending the concept of responsible innovation to include ENGOs as well as product developers (Tait and Banda 2018).

Opposition to GMOs and green biotechnology among some members of the public and civil society organisations, including particular ENGOs, may be largely based on interests, such as concerns about who benefits from applying the technology. If so, information and discussion may help to build trust in regulatory and other policy changes towards green biotechnology. Information must mean more than scientific data and discussion more than answering technical questions about how the data were acquired. Even if opposition to GM crops is based on interests, supplying data showing that GM crops increase yield may have little effect. People need context to interpret how those data affect their personal interests and reassurance that their interests have been acknowledged and understood, even if societal policy has contrary aims (Dietz 2013). If people feel they have been listened to, they may also be more open to arguments about re-evaluating their interests based on how their personal choices affect others.

Removing politics would strip scientific data of their context. An increase in yield from GM crops would be presented as unquestionably a good thing. People may bristle at this assumption and feel that their interests and values are being ignored by scientists and technocratic politicians and officials.
Better politics would seek discussions to understand what value people place on an increase in yield from GM crops and build arguments from there. Proponents of green biotechnology ought to be prepared to debate the "meaning" of higher yields from GM crops not simply assume that everyone thinks they are unequivocally beneficial or necessarily represent an increase in food security.

Better politics might also represent science as a process by which society gains knowledge to design and evaluate options for achieving its aims rather than as a body of facts ("the science") that determines those aims. Representing science as a process seems to be more effective in increasing trust in decisions that have a scientific component (Weisberg et al. 2021) and it correctly identifies scientific advisors as disinterested providers of analysis to help political leaders make the essential choices that only they ought to have the authority to make (Pielke 2007).

\section{Conclusion}

Many societies, particularly western democracies, have seen a long-term decline of trust in governmental intuitions (O'Neill 2002). An influential book by Peter Mair, Ruling the Void (2013), ascribes this loss of trust to "depoliticisation", the process by which decisionmaking is transferred from politicians to technocrats, leaving people with the feeling that they have no say on matters that control their lives.

Regulatory decision-making about GM crops and other green biotechnology has the air of depoliticisation. Public attention is focused on the deliberations of technical committees that request and analyse huge amounts of data. However, the aims of these committees and the decision-making criteria they use are not clear, giving the impression that science rather than public policy is in charge. This leads to loss of trust in the decision-making bodies but suits politicians who can avoid being seen to make controversial choices by outsourcing their decisions to "the science".

To realise the opportunities from GM crops and other green biotechnology, society must reverse this trend of depoliticisation. Rather than no politics, we need better politics that starts with political leaders who are willing to make, and be seen to make, ethical and political choices about societal objectives for food security and sustainable development and the role that 
green biotechnology can play in their accomplishment. Such clarity will encourage innovation because product developers will be confident that certain types of product will have a market. Political leadership is also required to set decision-making criteria that shift regulatory policy away from a fixation on short-term risk towards also managing long-term risk through encouraging innovation. Finally, better politics means discussing values so that information about green biotechnology has suitable context that encourages civil society to discuss biotechnology constructively. Greater openness about political aims, values and decision-making criteria should reduce behind-thescenes political meddling and opportunism in decision-making to the benefit of everyone apart from the meddlers and opportunists.

\section{References}

Bartsch D (2014) GMO regulatory challenges and science: a European perspective. J Fur Verbraucherschutz Und Lebensmittelsicherheit 9:51-58

Bonny S (2017) Corporate concentration and technological change in the global seed industry. Sustainability 9:1632

Crouch ML (1995) Biotechnology is not compatible with sustainable agriculture. J Agric Environ Ethics 8:98-111

Davison J (2010) GM plants: science, politics and EC regulations. Plant Sci 178:94-98

de Campos-Rudinsky TC, Undurraga E (2021) Public health decisions in the COVID-19 pandemic require more than 'follow the science.' J Med Ethics 47:296

Dietz T (2013) Bringing values and deliberation to science communication. Proc Natl Acad Sci 110:14081

Dinmohamed AG, Visser O, Verhoeven RHA, Louwman MWJ, van Nederveen FH, Willems SM, Merkx MAW, Lemmens VEPP, Nagtegaal ID, Siesling S (2020) Fewer cancer diagnoses during the COVID-19 epidemic in the Netherlands. Lancet Oncol 21:750-751

Herman RA, Storer NP, Anderson JA, Amijee F, Cnudde F, Raybould A (2021) Transparency in risk-disproportionate regulation of modern crop-breeding techniques. GM Crops \& Food 12:376-381

Hilbeck A, Binimelis R, Defarge N, Steinbrecher R, Székács A, Wickson F, Antoniou M, Bereano PL, Clark EA, Hansen M, Novotny E, Heinemann J, Meyer H, Shiva V, Wynne B (2015) No scientific consensus on GMO safety. Environ Sci Eur 27:4

Kafarski P (2012) Rainbow code of biotechnology. Chemik 66:814-816

Layton R, Smith J, Macdonald P, Letchumanan R, Keese P, Lema M (2015) Building better environmental risk assessments. Front Bioeng Biotechnol 3:110

Mair P (2013) Ruling the void: the hollowing of western democracy. Verso, London
Mastroeni M, Mittra J, Tait J (2021) Political influences on biotechnology-based innovation for European agriculture: risk-assessment and risk management. Technol Anal Strateg Manag 33:271-282

O’Neill O (2002) A question of trust. Cambridge Univeristy Press, Cambridge

Persson Å, Weitz N, Nilsson M (2016) Follow-up and review of the sustainable development goals: alignment vs. internalization. Rev Eur Comp Int Environ Law 25:59-68

Pielke RA (2007) The honest broker. Cambridge University Press, Cambridge

Raybould A (2019) Problem formulation and phenotypic characterisation for the development of novel crops. Transgenic Res 28:135-145

Raybould A, Macdonald P (2018) Policy-led comparative environmental risk assessment of genetically modified crops: testing for increased risk rather than profiling phenotypes leads to predictable and transparent decisionmaking. Fron Bioeng Biotechnol 6:43

Raybould A, Holt K, Kimber I (2019) Using problem formulation to clarify the meaning of weight of evidence and biological relevance in environmental risk assessments for genetically modified crops. GM Crops Food 10:63-76

Sanvido O, Romeis J, Gathmann A, Gielkens M, Raybould A, Bigler F (2012) Evaluating environmental risks of genetically modified crops: ecological harm criteria for regulatory decision-making. Environ Sci Policy 15:82-91

Smyth SJ, McHughen A, Entine J, Kershen D, Ramage C, Parrott W (2021) Removing politics from innovations that improve food security. Transgenic Res. https://doi.org/10. 1007/s11248-021-00261-y

Tait J (2001) More Faust than Frankenstein: the European debate about the precautionary principle and risk regulation for genetically modified crops. J Risk Res 4:175-189

Tait J, Banda G (2018) Proportionate and adaptive governance of innovative technologies. BSI, London

Tait J, Brown A, Lalinde IC, Barlow D, Chiles M, Mason P (2021) Responsible innovation: its role in an era of technological and regulatory transformation. Eng Biol 5:2-9

TIGRR (2021) Taskforce on innovation, Growth and Regulatory Reform. London, pp 130

Vollenbroek FA (2002) Sustainable development and the challenge of innovation. J Clean Prod 10:215-223

Weisberg DS, Landrum AR, Hamilton J, Weisberg M (2021) Knowledge about the nature of science increases public acceptance of science regardless of identity factors. Public Underst Sci 30:120-138

Whelan AI, Gutti P, Lema MA (2020) Gene editing regulation and innovation economics. Front Bioeng Biotechnol 8:303

Whyte J (2003) Bad thoughts: a guide to clear thinking. Corvo, London

Wilson AK (2021) 13 - Will gene-edited and other GM crops fail sustainable food systems? In: Kassam A, Kassam L (eds) Rethinking food and agriculture. Woodhead Publishing, pp 247-284

Publisher's Note Springer Nature remains neutral with regard to jurisdictional claims in published maps and institutional affiliations. 